\title{
FROM HARVESTING TO DISTILLATION - EFFECT OF ANALYTICAL PROCEDURES ON THE YIELD AND CHEMICAL COMPOSITION OF RHODODENDRON TOMENTOSUM (LEDUM PALUSTRE) ESSENTIAL OIL
}

\author{
ANNA JESIONEK'1, BOŻENA ZABIEGAŁA², ADAM BUCIŃSKI ${ }^{3}$ \\ and MARIA ŁUCZKIEWICZ**
}

\author{
'Department of Pharmacognosy with Medicinal Plant Garden, Medical University of Gdansk, \\ Hallera 107, 80-416 Gdańsk, Poland \\ ${ }^{2}$ Department of Analytical Chemistry, Gdańsk University of Technology, \\ Narutowicza 11/12, 80-233 Gdańsk, Poland \\ ${ }^{3}$ Department of Biopharmacy, Ludwik Rydygier Collegium Medicum in Bydgoszcz, \\ Nicolaus Copernicus University in Toruń, Jurasza 2, 85-089 Bydgoszcz, Poland
}

\begin{abstract}
Rhododendron tomentosum possesses the anti-inflammatory, analgesic and antimicrobial properties, determined by the chemical composition of its essential oil. The effects of place (Miszewko, Lubichowo) and time of harvesting (June, November) as well as drying (air-drying, oven-drying, freeze-drying) and isolation (in Deryng, Clevenger and Likens-Nickerson apparatus) procedures on the yield and quality of $R$. tomentosum essential oil were studied. Ledol (8.1-14.4\%), palustrol (6.9-13.0\%) and $\gamma$-terpineol (8.5-9.1\%) predominated in the plants collected from Miszewko, while $\gamma$-terpineol (11.8-22.2\%), p-cymene (5.3-12.6\%) and geranyl acetate $(5.7-7.5 \%)$ prevailed in the biomass from Lubichowo. The shoots produced more volatiles in the flowering phase than at the end of the vegetation. Oven-drying at $30^{\circ} \mathrm{C}$ with controlled air flow was suggested as the quick dehydration method. Hydrodistillation in Deryng and Clevenger apparatus resulted in comparatively high essential oil yield (about 1\%). All studied drying and distillation methods did not influence significantly the general profile of $R$. tomentosum essential oil.
\end{abstract}

Keywords: Clevenger apparatus, drying, Deryng apparatus, distillation, GC/MS analysis, Likens-Nickerson apparatus

Rhododendron tomentosum Harmaja (Ericaceae), formerly named as Ledum palustre L., can be found on the wetlands in northern and central Europe, Asia and North America (1). In some locations, for example in Poland, it is considered an endangered species, mainly due to the degradation and dewatering of its natural habitats (2). The extracts from the shoots were traditionally used not only to deter insects but also as a remedy for cold, cough and arthritis (1) as well as the aromatic beverage, native to North America (3). The modern researches demonstrated that the anti-inflammatory, analgesic, antioxidant, antimicrobial and repellent properties of $R$. tomentosum are associated to a large extent with the essential oil content (4-6).

As the predominant constituents of the $R$.tomentosum essential oil, ledol and palustrol are usually reported (7-10). However, as it is widely known, the chemical composition of the essential oils is variable and depends on the numerous factors, among others physiological, environmental and geographical conditions $(11,12)$. Moreover, the analytical procedures, such as drying of plant material and isolation of volatiles, may influence the essential oil yield and lead to qualitative and quantitative changes in its chemical composition due to volatility and thermolability of terpenoid compounds (13-15). A uniform analytical approach, not established for $R$. tomentosum so far, not only would enable to compare directly the literature data, but also would provide an indispensable tool for analysis of essential oil intended for medicinal purposes. Additionally, for the reason that excessive amount of ledol, the sesquiterpene alcohol with antitussive activity, is regarded as the potentially toxic agent for the central nervous system (1), monitoring of the $R$. tomento-

* Corresponding author: e-mail: mlucz@gumed.edu.pl 
sum essential oil seems to be particularly important. The aims of the study were to analyze the content and chemical composition of the essential oils obtained from $R$. tomentosum plants: 1) collected from two habitats in Poland (Lubichowo, Miszewko), 2) harvested at the end of flowering phase and at the vegetative growth stage (in June, in November), 3) dried under different conditions (airdrying, oven-drying, freeze-drying) and 4) subjected to various isolation methods (hydrodistillation in Deryng apparatus and in Clevenger apparatus, simultaneous distillation-extraction in LikensNickerson apparatus).

\section{MATERIALS AND METHODS}

\section{Plant material}

The aerial, non-ligneous parts of $R$. tomentosum (without flowers; without separating into young and last-year's shoots) were collected from two different habitats in Poland: in Lubichowo, approximately 70 km southeast of Gdansk (5349'49” N, 18 23 '44" E), and in Miszewko, approximately $20 \mathrm{~km}$ northeast of Gdansk (54'24'33" N, 18 $21^{\circ} 46^{\prime \prime}$ E). The harvesting was done in early June (VI) and in early November (XI) in 2016 (Table 1). Regional Director for Environmental Protection in Gdansk had granted permission to collect the plant material of the endangered species. Voucher specimens (no 14253 and no 14252, respectively) were deposited in the herbarium of Department of Biology and Pharmaceutical Botany, Medical University of Gdańsk.

\section{Drying procedures}

To study the effect of drying methods on the $R$. tomentosum essential oil yield and its composition, the plant material collected in Lubichowo in June was divided into four parts. One part was used for the analysis of fresh shoots (6 hours after harvesting; a control group) and the remaining portions were dried using one of the following procedures: (a) airdrying, in the shade, at $24^{\circ} \mathrm{C} \pm 2{ }^{\circ} \mathrm{C}$; (b) drying in a hot air oven, at $30^{\circ} \mathrm{C}$; (c) freeze-drying. Each part of the plant material contained 2 sets of $20 \mathrm{~g}$. Other samples (the plant material collected in Lubichowo in November as well as in Miszewko in June and November) were air-dried.

The harvested shoots were cut in about $5 \mathrm{~cm}$ segments. For air-drying (a) the biomass was spread over $1 \mathrm{~m}^{2}$ area on the sheets of gray paper and left under natural air flow, in the shade, at room temperature $\left(24^{\circ} \mathrm{C} \pm 2^{\circ} \mathrm{C}\right)$, for 8 days. Oven drying (b) was carried out in the drying chamber with forced convection (FD 115, Binder, Tuttlingen, Germany) at

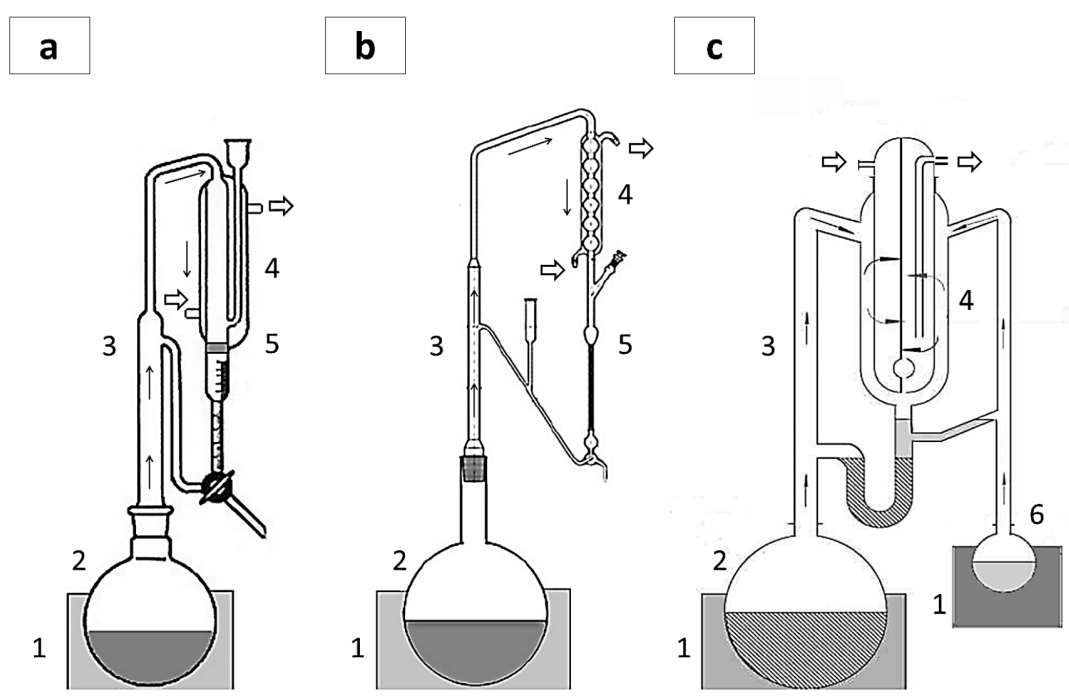

Figure 1. Schematic diagrams of apparatuses used in the study for the isolation of Rhododendron tomentosum essential oil: a) Deryng apparatus $^{\mathrm{a}}$, b) Clevenger apparatus ${ }^{\mathrm{b}}$, c) Likens-Nickerson apparatus $; 1$ heating mantle, 2 round-bottom flask with the plant material immersed in water, 3 fractionating column, 4 condenser, 5 distilling receiver with essential oil on the water surface, 6 extracting solvent (dichloromethane) with dissolved essential oil. Black and gray arrows indicate the flow of solvents (water and dichloromethane, respectively); white arrows indicate cooling water flow

a modified version of the picture according to ChemArgo, Blachownia, Poland (http://chemargo.com.pl)

ba modified version of the picture according to Bicchi and Maffei (34)

ca modified version of the picture according to the website http://www.fitness-vip.com/muscle-foods/simultaneous-distillation-extraction.html 
Table 1. The chemical composition of the essential oils obtained from Rhododendron tomentosum shoots collected from two different habitats: Lubichowo and Miszewko in Poland, in June (VI) and November (XI)a . Data by GC/MS ${ }^{\text {b }}$

\begin{tabular}{|c|c|c|c|c|c|c|}
\hline \multirow{3}{*}{ Compound } & \multirow{2}{*}{\multicolumn{2}{|c|}{ RI }} & \multicolumn{4}{|c|}{ Content in the essential oils (\%) } \\
\hline & & & \multicolumn{2}{|c|}{ Lubichowo, Poland } & \multicolumn{2}{|c|}{ Miszewko, Poland } \\
\hline & Study & NIST & VI & XI & VI & $\mathrm{XI}$ \\
\hline Thujene & 921 & 924 & 0.1 & - & 0.2 & - \\
\hline$\alpha$-Pinene & 937 & 931 & 1.2 & - & 0.8 & - \\
\hline Camphene & 948 & 947 & 1.0 & 1.5 & 0.4 & 0.5 \\
\hline Sabinene & 973 & 969 & 1.3 & 0.3 & 1.5 & 0.3 \\
\hline$\beta$-Pinene & 976 & 975 & 1.1 & 1.3 & 0.8 & 0.6 \\
\hline Myrcene & 995 & 988 & 0.4 & 0.1 & 3.7 & 3.1 \\
\hline$\alpha$-Phellandrene & 1011 & 1000 & 0.4 & 0.2 & 0.4 & 0.3 \\
\hline$\delta$-2-Carene & 1017 & 1002 & 6.6 & 0.5 & 7.0 & 0.2 \\
\hline$p$-Cymene & 1027 & 1025 & 5.3 & 12.6 & 4.0 & 4.5 \\
\hline Limonene & 1033 & 1032 & 1.7 & 1.5 & 1.4 & 1.4 \\
\hline (Z)- $\beta$-Ocimene & 1036 & 1034 & 0.9 & 0.5 & 0.8 & 1.7 \\
\hline (E)- $\beta$-Ocimene & 1050 & 1044 & 0.8 & 0.3 & 0.8 & 0.8 \\
\hline$\gamma$-Terpinene & 1059 & 1059 & 2.6 & 0.7 & 2.5 & 0.7 \\
\hline$\alpha$-Terpinolene & 1092 & 1078 & 0.7 & 0.5 & 0.6 & 0.2 \\
\hline Linalool & 1101 & 1100 & 0.2 & 0.6 & 1.0 & 0.3 \\
\hline Nonanal & 1105 & 1102 & 0.2 & 0.3 & - & - \\
\hline 1,3,8-p-Menthatriene & 1110 & 1113 & - & 0.3 & - & - \\
\hline cis- $p$-Ment-2-en-1-ol & 1119 & 1121 & 0.2 & 0.8 & - & - \\
\hline Alloocimene & 1125 & 1131 & 0.3 & - & 0.2 & 0.4 \\
\hline$\alpha$-Campholenal & 1128 & 1134 & - & 0.2 & - & - \\
\hline trans- $p$-Menth-2-en-1-ol & 1137 & 1140 & 0.1 & - & - & - \\
\hline trans-Pinocarveol & 1139 & 1141 & - & 1.2 & - & - \\
\hline Pinocarvone & 1159 & 1162 & 0.3 & 0.7 & 0.2 & 0.7 \\
\hline Borneol & 1175 & 1171 & - & 0.7 & - & - \\
\hline Terpinen-4-ol & 1179 & 1177 & 1.3 & 0.9 & 1.0 & 0.7 \\
\hline$\alpha$-Thujenal & 1186 & 1189 & 0.3 & - & 0.2 & 0.2 \\
\hline p-Cymen-8-ol & 1188 & 1187 & - & 1.4 & - & 0.4 \\
\hline$\alpha$-Terpineol & 1193 & 1190 & 0.2 & 0.5 & 0.1 & 0.2 \\
\hline Myrtenal & 1202 & 1196 & 0.5 & 0.9 & 0.2 & 1.0 \\
\hline $\begin{array}{c}\text { 2-Methyl-5-(fur-3-yl)-pent- } \\
\text { 3-en-2-ol }\end{array}$ & 1242 & 1239 & - & - & - & 0.7 \\
\hline$\gamma$-Terpineol ${ }^{\mathrm{c}}$ & 1245 & 1192 & 11.8 & 22.2 & 8.5 & 9.1 \\
\hline Geraniol & 1255 & 1256 & 0.5 & 1.6 & 0.5 & 2.3 \\
\hline Ascaridole & 1270 & 1273 & 0.6 & 1.3 & 0.3 & 1.0 \\
\hline Geranial & 1283 & 1240 & - & 0.5 & - & 0.1 \\
\hline Bornyl acetate & 1287 & 1292 & 4.5 & 5.7 & 2.0 & 3.0 \\
\hline Carvacrol & 1307 & 1299 & 0.3 & 0.9 & 0.2 & 1.0 \\
\hline Citronellyl acetate & 1356 & 1331 & 1.6 & 1.7 & 0.9 & 1.6 \\
\hline Geranyl acetate & 1387 & 1354 & 5.7 & 7.5 & 3.8 & 5.7 \\
\hline$\beta$-Elemene & 1400 & 1398 & 0.1 & - & 0.1 & - \\
\hline$\alpha$-Gurjunene & 1421 & 1419 & - & - & 0.3 & - \\
\hline
\end{tabular}


Table 1. Continued.

\begin{tabular}{|c|c|c|c|c|c|c|}
\hline \multirow{3}{*}{ Compound } & \multirow{2}{*}{\multicolumn{2}{|c|}{ RI }} & \multicolumn{4}{|c|}{ Content in the essential oils (\%) } \\
\hline & & & \multicolumn{2}{|c|}{ Lubichowo, Poland } & \multicolumn{2}{|c|}{ Miszewko, Poland } \\
\hline & Study & NIST & VI & $\mathrm{XI}$ & VI & $\mathrm{XI}$ \\
\hline Caryophyllene & 1431 & 1419 & 0.3 & - & 0.6 & - \\
\hline$\gamma$-Elemene & 1441 & 1433 & 0.3 & - & 0.1 & 0.1 \\
\hline (Z)- $\beta$-Farnesene & 1459 & 1446 & 0.1 & - & 0.1 & 0.1 \\
\hline$\alpha$-Humulene & 1466 & 1455 & 0.1 & - & 0.2 & - \\
\hline Alloaromadendrene & 1475 & 1462 & 1.8 & 1.3 & 2.0 & 2.0 \\
\hline Germacrene D & 1492 & 1482 & 0.4 & 0.4 & 0.2 & 0.1 \\
\hline 6-Epishyobunone & 1504 & 1480 & 2.6 & 0.2 & 2.0 & 0.1 \\
\hline$\alpha$-Muurolene & 1509 & 1499 & 0.3 & - & 0.3 & 0.2 \\
\hline Shyobunone & 1527 & 1510 & 5.7 & 0.5 & 4.4 & 0.3 \\
\hline$\delta$-Cadinene & 1533 & 1525 & 1.5 & 0.1 & 1.8 & 0.1 \\
\hline Isoshyobunone & 1537 & 1518 & 0.3 & 0.2 & 0.1 & 0.1 \\
\hline Palustrol & 1568 & 1562 & 0.8 & 3.8 & 6.9 & 13.0 \\
\hline Germacrene D-4-ol & 1576 & 1576 & 0.4 & - & 1.2 & - \\
\hline Caryophyllene oxide & 1583 & 1581 & 0.1 & 0.2 & 0.1 & 0.2 \\
\hline Viridiflorol & 1589 & 1588 & 0.1 & 0.3 & 0.2 & 0.9 \\
\hline Ledol & 1603 & 1605 & 2.3 & 3.5 & 8.1 & 14.4 \\
\hline Dehydroxyisocalamendiol & 1635 & 1616 & 0.5 & - & 0.2 & - \\
\hline$\tau$-Cadinol & 1638 & 1640 & 0.9 & 0.8 & 1.1 & 0.4 \\
\hline epi- $\alpha$-Muurolol & 1657 & 1644 & 0.1 & 0.3 & - & - \\
\hline$\alpha$-Cadinol & 1658 & 1654 & 1.1 & 3.3 & 1.4 & 0.5 \\
\hline \multicolumn{3}{|c|}{ Total $(\%)$} & 72.5 & 84.8 & 75.4 & 75.2 \\
\hline \multicolumn{3}{|c|}{ Essential oil yield $(\%)^{\mathrm{d}}$} & $2.19 \pm 0.1$ & $1.04 \pm 0.1$ & $3.39 \pm 0.2$ & $0.90 \pm 0.1$ \\
\hline
\end{tabular}

${ }^{a}$ after air drying at $24^{\circ} \mathrm{C}$ and hydrodistillation in Deryng apparatus; ${ }^{b}$ the data represents the means of two replicates; 'not clearly confirmed, on the basis of literature (9); ${ }^{\mathrm{d}} \mathrm{v} / \mathrm{w}$, the data represents the means of three replicates \pm standard deviation

$30^{\circ} \mathrm{C}$, for 3 days. The shoots, which were previously frozen for at least 24 hours at $-10^{\circ} \mathrm{C}$ (Liebherr freezer, Ochsenhausen, Germany), were freeze-dried in Steris Lyovac GT2 freeze dryer (Finn-Aqua Santasalo-Sohlberg, Tuusula, Finland) (vacuum: $1 \times$ 10-1 mbar, time: 72 hours) (c). To determine the required drying time for air-dried and oven-dried plant materials, their weight was measured every 24 hours till the constant value was obtained for 3 subsequent days. The loss of weight was used to calculate the loss of water in the samples (Table $2, \mathrm{n}=2$ ). The essential oil content was determined (Table 2, $\mathrm{n}=3$ ).

\section{Essential oil isolation procedures}

To study the effect of distillation methods on the $R$. tomentosum essential oil yield and its composition, the air-dried plant material collected in Lubichowo in November was divided into four parts containing 3 sets of $10 \mathrm{~g}$ each. The essential oils were isolated from the biomass using one of the following methods: (d) hydrodistillation in Deryng apparatus (a control group) (Fig. 1a) (16); (e) and (f) hydrodistillation in Clevenger apparatus without and with xylene addition, respectively (Fig. 1b) (17); (g) simultaneous distillation-extraction (SDE) in Likens-Nickerson apparatus (Fig. 1c) (18). Other samples (the plant material collected in Lubichowo in June and in Miszewko in June and November) were subjected to hydrodistillation in Deryng apparatus $(n=3)$.

For the determination of essential oil content in procedures (d) - (g), $10 \mathrm{~g}$ of the $R$. tomentosum plant material was immersed in $200 \mathrm{~mL}$ distilled water in a round-bottomed flask. Additionally, $0.3 \mathrm{~mL}$ xylene (Sigma, St Louis, USA) was added in the procedure (f). $30 \mathrm{~mL}$ dichloromethane (POCH, Gliwice, Poland) was employed as extracting solvent in SDE (g) (19). The schematics of the apparatuses used in the study are presented in Figure 1. The dis- 
tillation was performed for 3 hours, as described elsewhere (16-18). After quantitative determination on a scale of the distilling receiver, the essential oils obtained by method (d) and (e) were collected in 1.0 $\mathrm{mL}$ of hexane (Merck, Darmstadt, Germany) : diethyl ether (Sigma, St Louis, USA) mixture $(1: 1 v / v)(7)$ and dried over anhydrous sodium sulfate $(\mathrm{POCH}$, Gliwice, Poland). Afterward, the solvent was evaporated under a stream of nitrogen gas. The amount of the essential oil dissolved in the xylene layer (f) was calculated taking into account the loss of xylene in the hydrodistillation process. In SDE (g), the dichloromethane solution included volatiles was dried over anhydrous sodium sulfate. After evaporating the solvent under a stream of nitrogen gas, the obtained essential oil volume was measured by means of a glass pipette with a scale. The essential oil content in the studied plant materials was presented as a mean value of three replicates and expressed as a percentage $(\% v / w)$ (Table 1-3). All essential oil samples were stored at $4^{\circ} \mathrm{C}$, in $2 \mathrm{~mL}$ amber glass vials (Supelco, Bellefonte, USA), prior to analysis.

\section{GC/MS analysis of essential oils}

The chemical composition of the essential oils obtained from $R$. tomentosum shoots collected in
Lubichowo and Miszewko was determined by gas chromatography / mass spectrometry (GC/MS) using Gas Chromatograph 7890A coupled with Mass Selective Detector 5977A (Agilent Technologies, Santa Clara, US-CA). $1.0 \mu \mathrm{L}$ of the samples, diluted prior to analysis with ethyl acetate $(1: 80)$, was injected on the DB-5ms $30 \mathrm{~m} \times 0.25 \mathrm{~mm} \times 0.25$ $\mu \mathrm{m}$ capillary column (Agilent $\mathrm{J} \& \mathrm{~W}$ ) at $250^{\circ} \mathrm{C}$ with Agilent Autosampler Systems 7693, at a split ratio of $1: 10$. Helium was used as carrier gas at a constant flow rate of $1.1 \mathrm{~mL} / \mathrm{min}$. The oven temperature was programmed at $7^{\circ} \mathrm{C} / \mathrm{min}$ from an initial temperature of $50^{\circ} \mathrm{C}$ to $280^{\circ} \mathrm{C}$, which was held for $20 \mathrm{~min}$. The single GC/MS run time was $53 \mathrm{~min}$. The results were compared with the data (spectra, retention indices) from NIST Library 11.0 and were presented in Table 1 and Figure 2 as mean values from two replicates of the experiment.

\section{Statistical analysis}

The collected data were subjected to a one-way analysis of variance (ANOVA) followed by Duncan's Multiple Range test ( $\mathrm{p}<0.05)$ or HolmSidak test $(\mathrm{p}<0.05$, Multiple Comparisons versus Control Group). Analyses were conducted with SigmaPlot 11.0 (Systat Software, San Jose, US-CA).

Table 2. Effect of drying methods on the water loss and the essential oil content in Rhododendron tomentosum shoots collected in June in Lubichowo, in Poland.

\begin{tabular}{|c|c|c|c|}
\hline Drying method & Drying time (days) & Loss of water $(\%)^{\mathrm{a}}$ & Essential oil yield $(\%)^{\mathrm{b}}$ \\
\hline Fresh & - & - & $1.77 \mathrm{a} \pm 0.05$ \\
\hline Air-drying at $24^{\circ} \mathrm{C}$ & 8 & $38.86 \mathrm{a} \pm 0.37$ & $2.19 \mathrm{a} \pm 0.10$ \\
\hline Oven-drying at $30^{\circ} \mathrm{C}$ & 3 & $49.95 \mathrm{~b} \pm 1.50$ & $2.24 \mathrm{a} \pm 0.55$ \\
\hline Freeze-drying & 3 & $48.24 \mathrm{~b} \pm 0.59$ & $1.95 \mathrm{a} \pm 0.14$ \\
\hline
\end{tabular}

adetermined after drying process; values are the means of two replicates \pm standard deviation; data followed by different letters are significantly different at $\mathrm{p}<0.05$ (Duncan's Multiple Range); ${ }^{\mathrm{b}} v / w$, determined on DW basis, after hydrodistillation in Deryng apparatus; values are the means of three replicates \pm standard deviation; data followed by different letters are significantly different at $\mathrm{p}<0.05$ (Duncan's Multiple Range)

Table 3. Effect of isolation methods on the essential oil content in Rhododendron tomentosum shoots collected in November in Lubichowo, in Poland.

\begin{tabular}{|c|c|c|}
\hline \multirow{2}{*}{ Isolation method } & Type of apparatus & Essential oil yield (\%) $^{\mathrm{a}}$ \\
\hline \multirow{2}{*}{\begin{tabular}{c} 
Hydrodistillation \\
\cline { 2 - 3 }
\end{tabular}} & Deryng & $1.04 \mathrm{a} \pm 0.11$ \\
\cline { 2 - 3 } & $\begin{array}{c}\text { Clevenger } \\
\text { Clevenger (with xylene } \\
\text { addition) }\end{array}$ & $0.52 \mathrm{~b} \pm 0.09$ \\
\hline $\begin{array}{c}\text { Simultaneous extraction- } \\
\text { distillation }\end{array}$ & Likens-Nickerson & $0.95 \mathrm{a} \pm 0.06$ \\
\hline
\end{tabular}

${ }^{a} v / w$, determined on DW basis, after air drying at $24^{\circ} \mathrm{C}$; values are the means of three replicates \pm standard deviation; data followed by different letters are significantly different at $\mathrm{p}<0.05$ (Duncan's Multiple Range) 


\section{RESULTS AND DISCUSSION}

\section{Effect of place of harvesting}

The $R$. tomentosum plant material was collected from two habitats in Poland: Lubichowo and Miszewko. Both peatland areas have nearly the same longitude, with the $70 \mathrm{~km}$ distance between them. The essential oil yield obtained from the shoots collected in Miszewko in June was clearly higher than from those harvested in Lubichowo
(3.39 vs 2.19\%) (Table 1). Besides the geographical factor, this difference could also be caused by the age of the aerial parts. Although in both samples young and aged shoots were mixed together in half, the light green stems and leaves from Miszewko were rather finer than the slightly older, dark green biomass from Lubichowo. As it was stated before, the young $R$. tomentosum plant material is characterized with even 4-5-fold higher essential oil content in comparison with the aged shoots $(2,7)$.

a

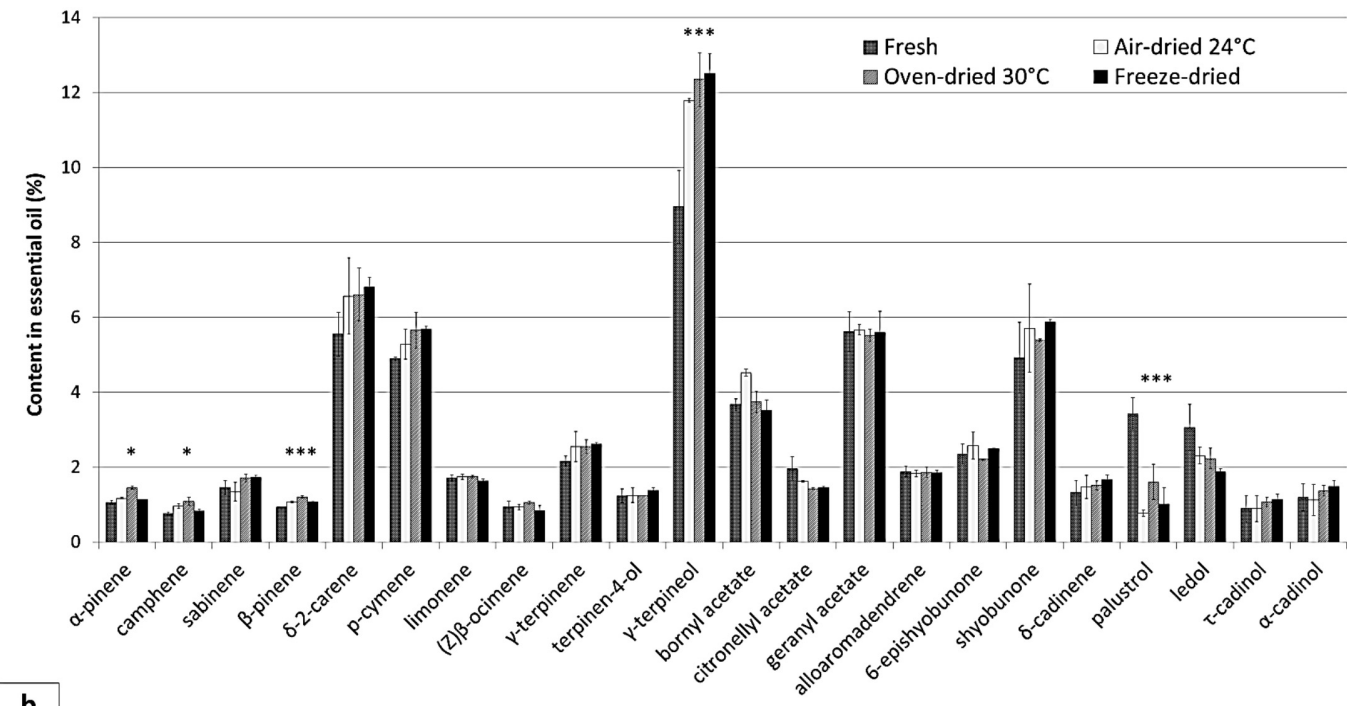

b

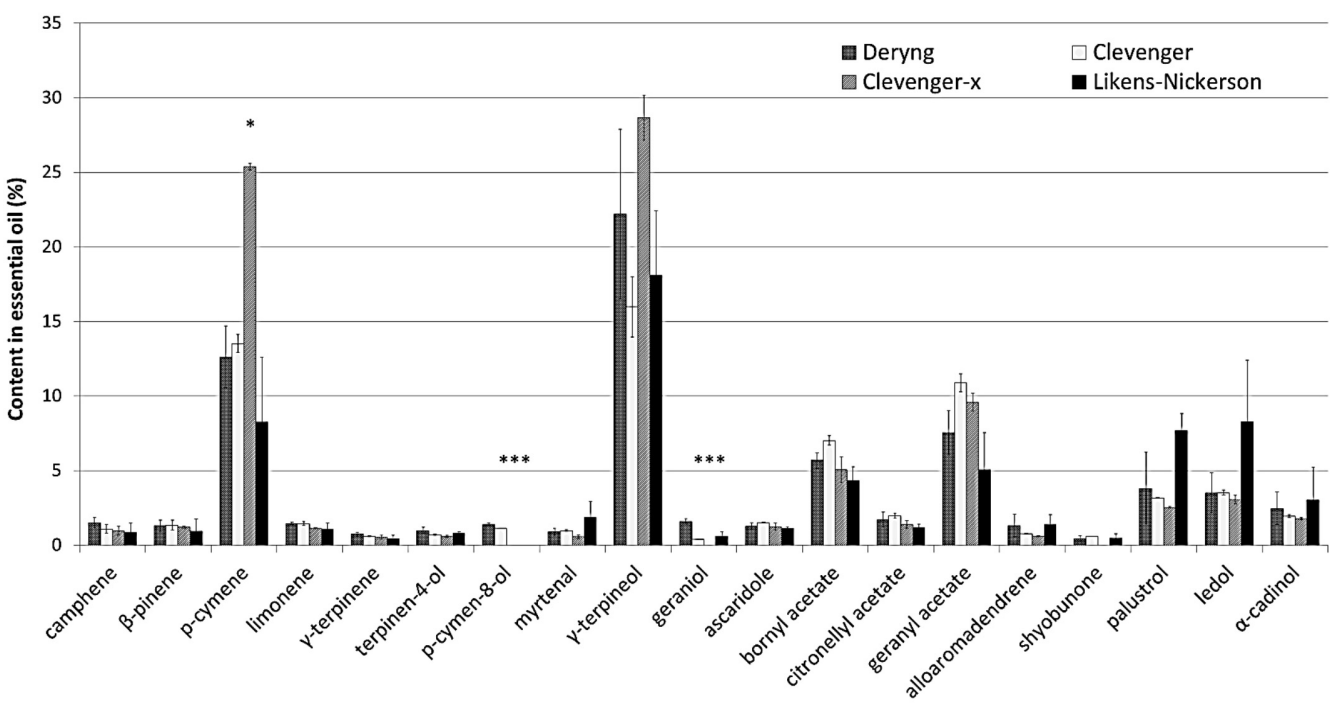

Figure 2. Effect of drying conditions (a) and isolation methods ${ }^{\mathrm{a}}$ (b) on the chemical composition of Rhododendron tomentosum essential oil (data by GC/MS)

${ }^{a}$ Clevenger; Clevenger-x - hydrodistillation in Clevenger apparatus without and with xylene addition, respectively

${ }^{b}$ values are the means of two replicates; data followed by an asterisk are significantly different at $\mathrm{p}<0.05$ (Holm-Sidak test, Multiple Comparisons versus Control Group); control groups: (a) fresh shoots, (b) Deryng apparatus 
The general profiles of the essential oils obtained from $R$. tomentosum collected in Poland in Miszewko and in Lubichowo were similar (Table 1) and did not vary greatly from the essential oils isolated from the plants growing in Lithuania and Estonia $(7,9,12)$. However, a few differences in the qualitative and quantitative composition could be noticed. 2-methyl-5-(fur-3-yl)-pent-3-en-2-ol and $\alpha$-gurjunene were present only in the essential oils obtained from the shoots harvested in Miszewko, while nonanal, cis- and trans- $p$-menth-2-en-1-ol, trans-pinocarveol and borneol were characteristic for $R$. tomentosum from Lubichowo. Some disparities in the proportions between the terpenoid compounds were also found in the essential oils from shoots collected in two studied habitats. Ledol (8.1\% and $14.4 \%)$, palustrol $(6.9 \%$ and $13.0 \%)$ and $\gamma$-terpineol $(8.5 \%$ and $9.1 \%)$ predominated in the plants from Miszewko, while $\gamma$-terpineol $(11.8 \%$ and $22.2 \%)$, p-cymene $(5.3 \%$ and $12.6 \%)$ and geranyl acetate $(5.7 \%$ and $7.5 \%)$ prevailed in the biomass from Lubichowo. The ledol and palustrol content in the essential oils obtained from $R$. tomentosum harvested in various habitats seems to be strongly diversified, which was also demonstrated by the literature data concerning the limited population of this species in Eastern Lithuania (12). Furthermore, the amount of myrcene in the essential oil of plants from Miszewko was eight times higher than in the second location $(3.1 \%$ and $3.7 \%$ vs $0.1 \%$ and $0.4 \%$, respectively). In turn, bornyl acetate content in the plant material from Lubichowo was twice as high as in another sample $(4.5 \%$ and $5.7 \%$ vs $2.0 \%$ and $3.0 \%$, respectively). The variations in the chemical composition of $R$. tomentosum essential oils may contribute to their different pharmacological profiles. The plant material abundant in ledol can be predicted to exert antitussive and antifungal effect of higher intensity $(1,20)$ than the one rich in $\gamma$-terpineol, the cytotoxic compound (21), or $p$ cymene, which possesses anti-inflammatory properties (22).

\section{Effect of time of harvesting}

Two periods of the growing season were selected for harvesting of $R$. tomentosum shoots in Lubichowo and in Miszewko: the turn of the flowering phase and the formation of seeds (early June) and the vegetative growth stage after seeding (early November). As it was observed, the studied plants produced from two to three times more essential oil in the reproductive phase than at the end of the vegetation (Table 1). The presence of young shoots in the samples harvested in June, which were rich in volatiles, may contribute to the following result. This tendency was in accordance with the outcomes obtained by Butkiene and Mockute (23), though in case of $R$. tomentosum collected in Lithuania in June and October the difference was less significant (1.73 vs $1.36 \%$ ). The observations of the discussed species in Moscow region suggested that the fluctuations of the essential oil content depend not only on the plant localities and the time of harvesting but also on the weather conditions in the subsequent years (24).

The chemical composition of the essential oils isolated from $R$. tomentosum harvested in early summer and in autumn varied considerably (Table 1). More monoterpene hydrocarbons (thujene, $\alpha$-pinene, sabinene, myrcene, $\delta$-2-carene, $\gamma$-terpinene, $\alpha$-terpinolene), sesquiterpene hydrocarbons ( $\beta$-elemene, caryophyllene, $\alpha$-humulene, $\alpha$-muurolene, $\delta$-cadinene) and some oxygenated sesquiterpenes (6-epishyobunone, shyobunone, germacrene D-4-ol, dehydroxyisocalamendiol, $\tau$-cadinol) were determined in the essential oils obtained from the samples collected in June in both studied habitats. In turn, the essentials oils from the plants taken from the peatlands in November abounded in oxygenated monoterpenes, such as $p$-cymen- 8 -ol, $\alpha$-terpineol, myrtenal, $\gamma$-terpineol, geraniol, ascaridole, geranial, bornyl acetate, and geranyl acetate. Moreover, in autumn the percentage of ledol and palustrol, sesquiterpenes with aromadendrane skeleton, was higher than in summer (Lubichowo: $2.3 \%$ vs $3.5 \%$ and $0.8 \%$ vs $3.8 \%$, respectively; Miszewko: $8.1 \%$ vs $14.4 \%$ and $6.9 \%$ vs $13.0 \%$, respectively). Although Evstratova et al. (24) did not report the regular change of ledol content in the $R$. tomentosum essential oils during the vegetation period, Butkiene and Mockute (23) confirmed that at the end of the growing season the essential oil was the richest in ledol and palustrol. From the furyl-containing compounds noticed previously by the last-mentioned authors (23), only 2-methyl-5-(fur-3-yl)-pent-3-en-2-ol was identified in the shoots from Miszewko (XI). Furthermore, it is noteworthy that the content of epi$\alpha$-muurolol and $p$-cymen-8-ol in the plant material from Miszewko (VI), which was demonstrated in our previous study (2), was not confirmed by the current experimental results. This discrepancy can prove the variability of $R$. tomentosum essential oil not only in the different stages of vegetation but also in the consecutive years.

\section{Effect of drying conditions}

In further phytochemical experiments, the plant material collected in Lubichowo was involved due to the larger population of $R$. tomentosum in this 
area than in Miszewko, which increased the availability of the biomass. The optimization of the drying process, an indispensable tool for postharvest preservation, storage and industrial production of pharmaceuticals, is necessary for each aromatic plant because of its influence on the quality of the raw material, among others its appearance and the chemical composition of the essential oil $(13,14)$. In our study, besides shade-drying, the traditional method of drying herbs, oven-drying and freezedrying were used. As in $R$. tomentosum, the essential oil is stored in glandular hairs on the leaf surface (2), the risk of its evaporation with water during drying is high. For this reason, in all selected techniques the applied temperatures did not exceed $30^{\circ} \mathrm{C}$ to protect the essential oils against the excessive loss and the decomposition of the bioactive ingredients.

As it is presented in Table 2, air-drying was the most time-consuming method. Moreover, after 8 days only $39 \%$ decrease of the initial weight was determined. On the contrary, after oven-drying and freezedrying, the loss of water was about $50 \%$ of the fresh weight. It could be associated not only with the more effective drying process but also with the loss of water from the interior of the plant material due to highspeed dehydration, which increased probability of simultaneous evaporation of volatiles (13). However, in all cases, the determined essential oil yield did not vary significantly and was about $2 \%$, which was similar to the essential oil content in $R$. tomentosum fresh shoots (Table 2). Although the influence of various drying methods on the essential oil content was shown in numerous researches $(14,25-27)$, some reports about the lack of this effect can also be found, especially concerning air-dried and oven-dried in the low temperatures plant material $(15,28)$.

The GC/MS results did not reveal many differences in the chemical composition of $R$. tomentosum essential oils depending on the drying method (Fig. 2a). Interestingly, although monoterpenes are more volatile than sesquiterpenes $(13,27)$, the enhancement of the monoterpene compounds level ( $\alpha$ - and $\beta$-pinene, camphene) was observed, especially after oven-drying. This phenomenon was also described by Sarosi et al. (28) in case of Thymus vulgaris. Furthermore, $\gamma$-terpineol amount was 30\% higher after drying process than in the $R$. tomentosum fresh biomass. On the other hand, as a result of dehydration palustrol percentage diminished over twice, while ledol level was reduced by one-third. Surprisingly, according to the literature data, the content of sesquiterpenes with aromadendrane skeleton in the essential oil of Thymus daenesensis (aromadendrene, ledene) increased after oven-dry- ing (14). In another report, these derivatives (alloaromadendrene, aromadendrene) were identified in the essential oil of Mentha longifolia only after drying in the oven (25).

On the basis of the above results, showing that the obtained essential oils were characterized with similar quality, it is difficult to suggest one optimal drying method for $R$. tomentosum plant material. Although air-drying is cost-effective, it requires a large area to spread the shoots and the long drying period. The application of freeze-drying can prevent adverse microbiological reactions; however, the cost of this procedure is several times higher than conventional methods (13). Taking the disadvantages of each drying method into account, oven-drying, the quick dehydration process with controlled parameters (temperature, air flow), seems to be the most suitable for $R$. tomentosum shoots.

\section{Effect of isolation method}

The essential oils of $R$. tomentosum reported so far in the literature were obtained not only from the plant materials collected in different locations but also using various isolation methods, which impedes the comparison of the samples (1). In our study, the most common methods applied for the isolation of the $R$. tomentosum essential oil, such as hydrodistillation in Deryng apparatus (2) and in Clevenger apparatus $(4,12)$ as well as simultaneous distillation-extraction (SDE) $(9,29)$ in Likens-Nickerson apparatus, were tested to assess their impact on the chemical composition of the plant volatiles. Although only the product isolated by hydrodistillation or steam distillation can be in fact called as "essential oil" (30), in this text for simplicity reasons this term was also used for the concentrated SDE-extract.

The content of the essential oil in $R$. tomentosum plant material differed significantly depending on the isolation method (Table 3). The most efficient process was hydrodistillation in Deryng apparatus as well as in Clevenger apparatus using xylene layer for volatiles accumulation, as recommended in Polish Pharmacopoeia X (17) (1.04 and 0.95\%, respectively). However, omitting the addition of xylene in the last method resulted in the determination of twice lower content of essential oil than otherwise, which could be caused by deposition of the essential oil not only in the receiver but also in the small diameter glass tubes of apparatus. Similarly, SDE method was characterized with the loss of the obtained essential oil in comparison with a control group $(0.79 \%)$, probably due to the fact that content of volatiles was measured only after further experi- 
mental procedures: drying over anhydrous sodium sulfate and concentration by evaporation of large volume of the organic solvent, which could decrease the extraction capacity (31). Moreover, the prolongation of time of performing SDE should be considered $(9,19)$. In the monograph of Ledi palustris cormus, included in the State Pharmacopoeia of the USSR (32), the recommended hydrodistillation time is 4 hours.

The chemical composition of the $R$. tomentosum essential oils obtained with various methods was, to a great extent, similar (Fig. 2b). The addition of xylene during hydrodistillation in Clevenger apparatus resulted in a noticeable increase in $p$-cymene and $\gamma$-terpineol amount (by 50\% and 20\%, respectively). In turn, the essential oil collected in LikensNickerson apparatus was characterized by the lowest content of monoterpene hydrocarbons. On the other hand, it was the richest in aromadendrane derivatives (alloaromadendrene, palustrol, ledol). p-Cymen-8-ol, a monoterpenoid alcohol, was identified only in the essential oil distilled in Deryng and Clevenger apparatuses (without xylene addition). The construction of the glass apparatuses for hydrodistillation was reported previously to have little effect on the qualitative and quantitative composition of the essential oil of Mutellina purpurea (33), which is consistent with our observations.

The obtained results allowed to evaluate the influence of isolation in Deryng, Clevenger and Likens-Nickerson apparatuses on the content and the terpene components of $R$. tomentosum essential oils. So far, supercritical $\mathrm{CO}_{2}$ extraction and hydrodistillation in Clevenger apparatus were compared with regard to $R$. tomentosum essential oil (4). However, in case of SFE method (90 bar and $40^{\circ} \mathrm{C}$ ) yield of extracted volatile compounds was lower than that of distilled essential oil $(1.5 \%$ vs $2.0 \%$, respectively) (4). Although in our study only a few significant changes in the chemical composition of the essential oils isolated with various methods were observed, hydrodistillation process in Deryng apparatus seems to be the most beneficial in view of the high yield and the possibility of the determination even small volume of the essential oil, avoiding enrichment it in interfering organic substances (xylene, dichloromethane) before the measurement.

\section{CONCLUSIONS}

In conclusion, it was proved that many parameters, including analytical procedures, can affect the yield of $R$. tomentosum essential oil and its chemical composition. First of all, the selection of the proper plant chemotype, as well as the habitat abounding in individuals, to provide a constant source of volatiles to further studies are necessary. Moreover, the fluctuations of the essential oil content depending on the time of harvesting should be taken into account. The $R$. tomentosum samples from June contained more monoterpene and sesquiterpene hydrocarbons while in the essentials oils obtained in November larger amount of oxygenated monoterpenes as well as ledol and palustrol was detected. Subsequently, the optimal drying method should be used. On the basis of our results, oven-drying at $30^{\circ} \mathrm{C}$ with controlled air flow can be recommended to the quick dehydration. Finally, the efficient isolation method, suitable for thermolabile plant aroma, should be chosen. Hydrodistillation of $R$. tomentosum plant material in Deryng and Clevenger apparatus (with the addition of xylene) resulted in comparatively high essential oil yield, indicating the usefulness of these classic approaches to volatile compounds isolation.

\section{Acknowledgments}

This work was supported financially by a grant from the National Science Center in Poland [decision no. UMO-2014/15/N/NZ7/03027].

The authors are thankful to W. Jesionek (Institute of Political Sciences, University of Gdansk) for the help in the plant material harvesting, and Dr. N. Filipowicz for the deposition of voucher specimens in the herbarium of Department of Biology and Pharmaceutical Botany, Medical University of Gdańsk.

\section{Author contributions}

AJ designed all experiments, collected the plant material, conducted the phytochemical experiments (drying, isolation of volatiles), analyzed the data and prepared the manuscript. BZ developed the GC/MS method for analysis of the chemical composition of the studied essential oils and analyzed the data. AB corrected the manuscript. ML conceptualized and supervised the study, analyzed the data and corrected the manuscript.

All co-authors agree to submit this manuscript. It has not been submitted to any other journal for simultaneous consideration. The authors have no conflict of interest to declare.

\section{REFERENCES}

1. Dampc A., Luczkiewicz M.: Fitoterapia 85, 130 (2013). 
2. Jesionek A., Kokotkiewicz A., Wlodarska P., Filipowicz N., Bogdan A. et al.: Acta Biol. Crac. Ser. Bot. 58, 29 (2016).

3. Dampc A., Luczkiewicz M.: J. Sci. Food Agric. 95, 1577 (2015).

4. Baananou S., Bagdonaite E., Marongiu B., Piras A., Porcedda S. et al.: Nat. Prod. Res. 29, 999 (2015).

5. Jaenson T.G., Palsson K., Borg-Karlson A.K.: Med. Vet. Entomol. 19, 345 (2005).

6. Kim D.-M., Nam B.-W.: Prev. Nutr. Food Sci. 11, 100 (2006).

7. Butkiene R., Sakociute V., Latvenaite D., Mockute D.: Chemija 19, 19 (2008).

8. Klokova M.V., Khan V.A., Dubovenko Zh.V., Pentegova V.A., Berezovskaya T.P. et al.: Chem. Nat. Compd. 19, 278 (1983).

9. Raal A., Orav A., Gretchushnikova T.: Nat. Prod. Res. 28, 1091 (2014).

10. Tattje D.H., Bos R.: Planta Med. 41, 303 (1981).

11. Figueiredo A.C., Barroso J.G., Pedro L.G., Scheffer J.J.C.: Flavour Fragr. J. 23, 213 (2008).

12. Judzentiene A., Budiene J., Misiunas A., Butkiene R.: Chemija 23, 131 (2012).

13. Orphanides A., Goulas V., Gekas V.: Food Eng. Rev. 8, 164 (2016).

14. Rahimmalek M., Goli S.A.H.: Ind. Crops Prod. 42, 613 (2013).

15. Sefidkon F., Abbasi K., Khaniki G.B.: Food Chem. 99, 19 (2006).

16. Polish Pharmacopoeia, Vol. VI, PTFarm, Warsaw 2002 (in Polish).

17. Polish Pharmacopoeia, Vol. X, PTFarm, Warsaw 2014 (in Polish).

18. Likens S.T., Nickerson G.B.: Proc. Am. Soc. Brew Chem. 5 (1964).
19. Laohaprasit N., Ambadipudi D.S., Srzednicki G.: Inter Food Res. J. 18, 1043 (2011).

20. Duran-Pena M.J., Botubol J.M., Hanson J.R., Collado I.G., Hernandez-Galan R.: Nat. Prod. Rep. 32, 1236 (2015).

21. Wu Z.-L., Yin Z.-Q., Du Y.-H., Feng R.-Z., Ye K.-C. et al.: Int. J. Clin. Exp. Pathol. 7, 6524 (2014).

22. Bonjardim L.R., Cunha E.S., Guimaraes A.G., Santana M.F., Oliveira M.G.B. et al.: Z. Naturforsch. 67c, 15 (2012).

23. Butkiene R., Mockute D.: J. Essent. Oil Res. 23, 9 (2011).

24. Evstratova R.I., Kabanov V.S., Krylova I.L., Prokosheva L.I.: Pharm. Chem. J. 12, 1468 (1979).

25. Asekun O.T., Grierson D.S., Afolayan A.J.: Food Chem. 101, 995 (2007).

26. Fathi E., Sefidkon F.: J. Agr. Sci. Tech. 14, 1035 (2012).

27. Sellami I.H., Wannes W.A., Bettaieb I., Berrima S., Chahed T. et al.: Food Chem. 126, 691 (2011).

28. Sarosi S., Sipos L., Kokai Z., Pluhar Z., Szilvassy B. et al.: Ind. Crops Prod. 46, 210 (2013).

29. Gretsusnikova T., Jarvan K., Orav A., Koel M.: Procedia Chem. 2, 168 (2010).

30. Rubiolo P., Sgorbini B., Liberto E., Cordero C., Bicchi C.: Flavour Fragr. J. 25, 282 (2010).

31. Chaintreau A.: Flavour Fragr. J. 16, 136 (2001).

32. The State Pharmacopoeia of the USSR, Medizina, Moscow 1990 (in Russian).

33. Baj T., Sieniawska E., Kowalski R., Wesołowski M., Ulewicz-Magulska B.: Acta Pol. Pharm. 72, 507 (2015).

34. Bicchi C., Maffei M.: Methods Mol. Biol. 918, 289 (2012).

Received: 05.10.2018 